\title{
Takım Sporlarında Paylaşılan Zihinsel Modeller Ölçeği’nin Türk Sporculara Yönelik Sınanması: Geçerlik ve Güvenirlik Çalışması
}

\author{
Utku IŞIK ${ }^{1 *} \mathbb{D}$, Osman GÜMÜŞGÜL ${ }^{2}$ \\ ${ }^{1}$ Recep Tayyip Erdoğan Universitesi, Rize. \\ ${ }^{2}$ Dumlupınar Universitesi, Kütahya.
}

Orijinal Makale

Gönderi Tarihi: 13.05.2020
Kabul Tarihi: 07.06.2020
DOI: $10.25307 /$ jssr. 737128

Online Yayın Tarihi: 30.06 .2020

Öz

Takım Sporlarında Paylaşılan Zihinsel Modelin işlevi, ekip üyelerinin takım arkadaşlarınınkilerle tutarlı ve koordineli eylemleri seçmek için bir kaynak olarak kendi iyi yapılandırılmış bilgilerini kullanmalarına izin vermektir. Bu kapsamda bu çalışmanın amacı bireysel başarıların ekip başarısına dönüşmesi adına Takım Sporlarında Paylaşılan Zihinsel Modeller Ölçeği'nin (TSPZMÖ) Türk sporcularına olarak yönelik sınanmasıdır. Çalışmanın örneklem grubunu uygun örnekleme metoduyla belirlenen ve Türkiye'de farklı amatör liglerde futbol, voleybol, hentbol ve basketbol oynayan yaşları 15 ila 39 arasında değişen $\left(\mathrm{X}_{\text {yaș }}=2.60+/-3,64\right) 330$ sporcu oluşturmuştur. Bu araştırma, Gershgoren (2012) tarafindan geliştirilen "Shared Mental Models in Team Sports Questionnaire" ölçeğinin faktör yapısı test edilmiş, ölçeğin hem 13 hem de 3 alt boyutlu yapılarının geçerlilik ve güvenirlilik çalışması gerçekleştirilmiştir. Ölçeğin uyarlanması belirli aşamalardan geçmiştir. Öncelikle dilsel eşdeğerlik çalışması yapılmıştır. Ölçek daha sonra sırasıyla kapsam geçerliliği, yapı geçerliliği, yakınsak geçerlilik ve ayrışma geçerliliği analizlerine tabii tutularak son şeklini almıştır. Ayrıca ölçeğin güvenirliliğine ise Cronbach's Alpha iç tutarlılık katsayısı kullanılmıştır. Yapılan analizler sonucunda geçerlik ve güvenirlik testlerinden elde edilen puanlar Takım Sporlarında Paylaşılan Zihinsel Modeller Ölçeği’nin 49 maddeli ve 13 alt boyutlu yapısını desteklemektedir. 3 alt boyutlu yapı için ayrıca yapılan geçerlilik ve güvenirlilik çalışması sonucunda da ölçeğin Türk sporcular için uygun olduğuna karar verilmiştir. Takım Sporlarında Paylaşılan Zihinsel Modeller Ölçeği, paylaşılan zihinsel modellerin genel özelliklerini değerlendirmek ve takım üyelerinin özel ve genel bilişsel yapıları ile etkinlik inançları hakkındaki değerlendirmeleri için kullanılabilir.

Anahtar kelimeler: Takım Sporları, Paylaşılan Zihinsel Modeller, Geçerlilik, Güvenirlik.

\section{Turkish Adaptation of the Shared Mental Models in Team Sports Scale: Validity and Reliability Study}

\begin{abstract}
The Shared Mental Model in Team Sports is to allow team members to use their own well-structured knowledge as a resource to select actions consistent and coordinated with their teammates. In this context, the aim of the study was to test Shared Mental Models Scale to Turkish athletes with the aim of turning individual achievements into team success. The sample of the study, which was determined by convenience sampling method, was 330 athletes including amateur football, volleyball, handball and basketball players from different categories in Turkey, ranging from ages 15 to $39\left(\mathrm{X}_{\mathrm{age}}=2.60+/-\right.$ 3,64). In this study, the factor structure of the Shared Mental Models in Team Sports Scale, developed by Gershgoren (2012) was tested, and the validity and reliability study of both 13 and 3 sub-scales structures of the scale were performed. The adaptation of the scale went through certain stages. Firstly, linguistic equivalence study was carried out. The scale was then subjected to content validity, construct validity, convergent validity and decomposition validity, respectively. In addition, Cronbach's Alpha internal consistency coefficient was used for the reliability of the scale. As result of the analyses, the scores obtained from the validity and reliability tests support the 49-item and 13 sub-scales structures of the Mental Model Shared in Team Sports. Besides; as a result of the validity and reliability study for 3 sub-dimensional structures, it was decided that the scale was applicable for Turkish athletes. The Shared Mental Models in Team Sports Scale can be used to evaluate the general characteristics of shared mental models and to evaluate team members' specific and general cognitive structures and efficacy beliefs.
\end{abstract}

Keywords: Team sports, Shared mental models, Validity, Reliability.

\footnotetext{
* Sorumlu Yazar: Utku IŞIK, E-posta: utku.isik@erdogan.edu.tr
} 


\section{GíRiș}

Zihinsel model terimi literatürde ilk kez Craik (1943) tarafından insan davranışı ve bilişsellik konusundaki çalışmaları ile kullanılmaya başlanmıştır. Zihinsel model, nesneleri, koşulları, olguları ve insanları tanımlamayı ve tahmin etmeyi sağlayan içsel bir betimleme olarak tanımlanmaktadır (Goldshmidt \& Surasky, 2011). Goldschmidt (2017), insanların davranış ve düşünceyi yönlendiren zihinsel modellere göre hareket ettiğini savunmaktadır. Zihinsel modeller, insanların sıklıkla kültür olarak adlandırdıkları kavramsal çerçevenin ürünüdür. Burada kültür, bireysel karar vermeyi etkilemektedir, çünkü insanların hareket ve tercihlerinde kullandıkları birbiri ile ilgili anlamlandırma şemalarının bir kümesi olarak görev yapmaktadır. Bu anlamlandırma şemaları, karar verme aşamasında uygulanacak hareketin etkinleştirilmesi ve yönlendirilmesi için bir araç niteliğindedir (Yazıcı ve Düzkaya, 2016).

Filozof Sartre'a (2002) göre, bireysel eylem, amacını ortak amaçta bulur. Sartre, takımın kolektif kuralları hakkında bilgi sahibi olmadan bireysel olarak takım oyuncularının eylemlerini anlamanın imkânsız olduğunu belirtmektedir. Elit bir takımdaki ortak düşünceler, paylaşılan bir zihinsel model (PZM) olarak kavramsallaştırılabilir. Cannon-Bowers vd. (1993), Paylaşılan Zihinsel Modeli ekip üyeleri tarafından görev için doğru açıklamalar ve beklentiler oluşturmalarını sağlayan bilgi yapıları olarak eylemleri koordine etmek; davranışlarını görevin ve diğer ekip üyelerinin taleplerine uyarlamak olarak tanımaktadır.

Takım sporlarında her takım üyesinin kendi zihinsel modeli vardır. Ancak, takım başarısından söz edebilmek için takımın zihinsel modelleri paylaşması gerekmektedir. $\mathrm{Bu}$ nedenle takım üyeleri, görüşlerini tartışmak ve görüş alışverişinde bulunmak için zihinsel modellerini dışsallaştırmaktadır (Goldshmidt \& Surasky, 2011). Takım çalışmasında ortak zihinsel model, paylaşılan zihinsel modellerle elde edilir (Langan-Fox vd., 2004). Arnesen (2019), takım sporlarında paylaşılan zihinsel modellerinin, bir ekibin üyeleri arasında görevin doğru açıklamalarını ve beklentilerin oluşturmasını ve ardından eylemlerini koordine etmelerini ve davranışlarını görevin gereksinimlerine ve diğer ekip üyelerine uyarlamalarını sağlayan ortak bir bilgi yapısı olduğunu vurgulamıştır.

Takım sporlarında paylaşılan zihinsel model oluşumunda takım üyelerinin zihinsel model aktarımları için dil en önemli etken olarak görülmektedir. Bununla birlikte; görsel imgeleme takım sporlarında paylaşılan zihinsel modelde önemli bir anahtardır (Goldschmidt, 2017). Bu nedenle, takım sporlarında paylaşılan zihinsel modeller üzerinde yapılan bir araştırmada, sözlü iletişim kadar antrenör ve sporcular arasındaki görsel iletişim de dikkate alınmalıdır. Takım sporlarında bireyler arasında etkileşim ve paylaşılan zihinsel modeller yeni bilgi ve yaratıcı sonuçlar getirmektedir (Rouse ve Morris, 1986). Örneğin bir takımda, her takım üyesi kendi zihinsel modelini birkaç müsabakayla diğer takım üyelerine aktarabilir. Paylaşılan zihinsel model, diğer ekip üyesinin zihinsel modeli için bir uyarıcıdır. Bu uyaran her takım üyesinin zihninde farklı bilgiler uyandırabilmektedir. Zihinsel model aktarımı sürecinde, tüm zihinsel modeller ve dişsal zihinsel modeller (temsiller) yeni bir ortak zihinsel model oluşturmak için birbirleriyle etkileşime girmektedir. Bu süreçte, akıl yürütmek ve bilginin dönüşümü yaratıcı sonuçlara yol açabilmektedir. Ayrıca, bu süreçte dışsallaştırılan zihinsel modellerin her zaman görsel olması da gerekmemektedir. Bir kelime, bir ses de 
dişsal bir temsildir. Böylece, bu temsiller zihinsel modelle etkileşime girebilmektedir ve yeni bir sonuç yaratmaktadır (Yazıcı, 2018).

Takım Sporlarında Paylaşılan Zihinsel Modelin işlevi, ekip üyelerinin takım arkadaşlarınınkilerle tutarlı ve koordineli eylemleri seçmek için bir kaynak olarak kendi iyi yapılandırılmış bilgilerini kullanmalarına izin vermektir. Uyarlanmış bu model, durumsal biliş: öngörü, yaratıcılık, birbirini tanıma, deneyim; genel biliş: beceriyi maksimuma çıkartma, oyuncunun pozisyon uyumu, denge, antrenör-sporcu uyumu, takım uyumu, takım hedefleri; yeterlilik inancı: öz yeterlilik, diğerlerinin yeterliliği, takım yeterliği olarak 3 üst alt boyut ve 13 alt boyut şeklinde oluşturulmuştur.
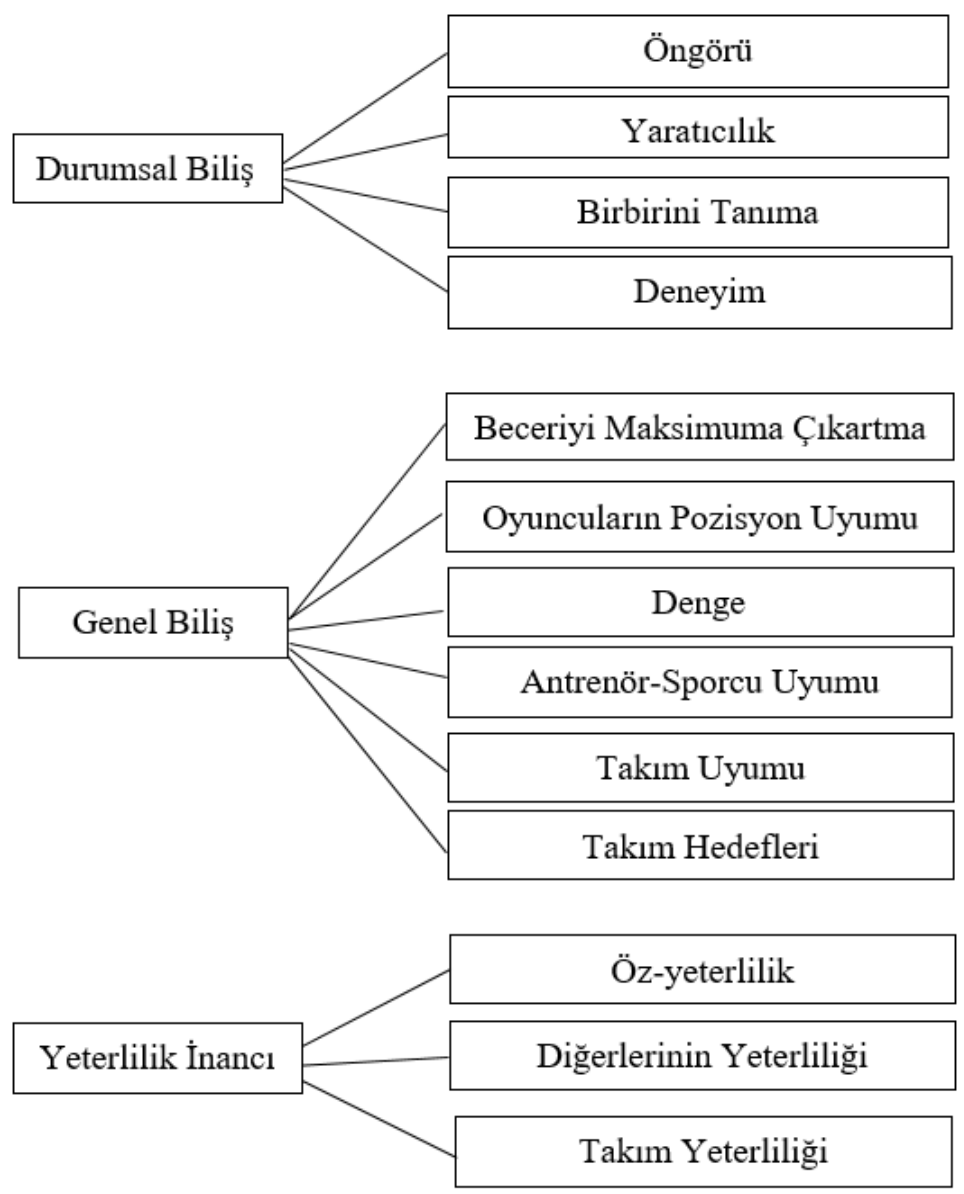

Şekil 1. Takım Sporlarında Paylaşılan Zihinsel Modeller Uyarlanmış Formu

Spor bilimleri araştırmalarının çok azı (Apitzsch, 2009; Becker vd., 2003; Burk vd., 2006; Bourbousson vd., 2010; Canon Bowers ve Bowers, 2006; Eccles ve Tenenbaum, 2004; Gershgoren vd., 2013; Ward ve Eccles, 2006), takım sporlarında paylaşılan zihinsel modeller konusunu, takım sporlarında eğitiminin nasıl tasarlandığını ve verildiğini, özellikle de bireysel oyuncuları koordineli bir ekibe dönüştüren bilişsel faktörleri incelemişlerdir. Bu kapsamda bireysel başarıların ekip başarısına dönüşmesi adına Takım Sporlarında Paylaşılan Zihinsel Modeller Ölçeği’ nin Türkçe uyarlaması oldukça önemli görülmektedir. 


\section{METOT}

Araştırma Modeli: Bu araştırma, Gershgoren (2012) tarafından geliştirilen "Shared Mental Models in Team Sports Questionnaire" ölçeğinin faktör yapısının test edildiği metodolojik bir araştırmadır. Araştırma nicel araştırma paradigması temel alınarak tarama modeline göre tasarlanmıştır.

Evren ve Örneklem: Çalışmanın evrenini Türkiye'de farklı amatör liglerde futbol, voleybol, hentbol ve basketbol oynayan bireylerden oluşmaktadır. Çalışmanın örneklem grubunu ise uygun örnekleme (convenience sampling) metoduyla belirlenen ve Türkiye'de farklı amatör liglerde futbol, voleybol, hentbol ve basketbol oynayan yaşları 15 ila 39 arasında değişen $\left(\mathrm{X}_{\mathrm{yas}}=2.60+/-3,64\right) 330$ sporcu oluşturmuştur.

Veri Toplama Aracı: Çalışmanın temelini oluşturan "Shared Mental Models in Team Sports Questionnaire" ölçeği 3 üst boyut (ölçek) ve 13 alt boyuttan oluşmakta ve takım sporu yapan sporcuların takım arkadaşları, antrenörleri ve kendileri ile ilgili görüşlerini ortaya koyan 50 maddelik bir ölçektir. Shared Mental Models'i odak noktasında alan bu ölçek Gershgoren (2012) tarafindan ortaya konmuştur.

Ölçeğin Türkçe geçerlilik ve güvenirlilik çalışması için çalışmanın yazarı olan Dr. Lael Gershgoren ile elektronik posta yoluyla iletişime geçilmiş ve gerekli izinler alınmıştır. Ölçeğin 50 maddelik formunda 13 alt boyut yer almaktadır ve bu 13 alt boyut SMM modeline uygun olarak 3 üst alt boyutta birleştirilmiştir. Gershgoren (2012) yaptığı çalışmada hem 13 alt boyutlu yapıda hem de 3 alt boyutlu yapıda geçerlilik ve güvenirlilik çalışmasını gerçekleştirmiştir. 50 maddelik yapıda son soru olan "Genel olarak, takımınızdaki oyuncular sahada birbirleriyle uyum içindedirler" sorusu ölçek geliştirme aşamalarında kullanılmamıştır. Bu soru sadece genel bir değerlendirme için sporculara sorulduğundan ölçek geliştirme aşamalarında bu soru hem orijinal çalışmada hem de bu çalışmada yapılara dahil edilmemiştir. 13 alt boyut ve 3 üst boyut ise şu şekilde isimlendirilmiştir ve gruplandırılmıştır; öngörü (4 madde), birbirini tanıma (4 madde), yaratıcılık (4 madde), deneyim ( 2 madde) alt boyutları Durumsal Bilişsellik üst boyutunda; beceriyi maksimuma çıkartma (4 madde), oyuncuların pozisyon uyumu (4 madde), denge (4 madde), antrenör sporcu uyumu (3 madde), takım uyumu ( 3 madde) ve takım hedefleri (5 madde) Genel Bilişsellik üst boyutunda; özyeterlilik ( 4 madde), diğerlerinin yeterliliği (4 madde), takım yeterliliği (4 madde) alt boyutları ise Yeterlilik İnançları üst boyutunda incelenmektedir.

Dr. Lael Gershgoren ile gerçekleştirilen mailleşme ve Gershgoren'in (2012) doğrultusunda ölçeğin hem 13 alt boyutlu bir yapıda hem de 3 üst boyutlu bir yapıda geçerlilik ve güvenirlilik çalışmasının yapılmasının uygun olacağına karar verilmiştir.

Verilerin Toplanması: Veriler Google formlar aracılığı ile araştırmacıların kişisel çabaları ile Türkiye'de farklı amatör liglerde futbol, voleybol, hentbol ve basketbol oynayan katılımcıların gönüllü katılımı ile toplanmıştır. 
Verilerin Analizi: "Shared Mental Models in Team Sports Questionnaire" ölçeğinin Türkçe'ye uyarlanması belirli aşamalardan geçmiştir. Öncelikle dilsel eşdeğerlik çalışması yapılmıştır. Ölçek daha sonra sırasıyla kapsam geçerliliğii, yapı geçerliliği, yakınsak geçerlilik ve ayrışma geçerliliği analizlerine tabii tutularak son şeklini almıştır. Ayrıca ölçeğin güvenirliliğine ise cronbach alfa iç tutarlılık katsayısı ile ulaşılmıştır. Verilerin analizinde Microsoft Excel, IBM SPSS 24.0 ve IBM SPSS Amos 22.0 programları kullanılmıştır.

Çalışma Recep Tayyip Erdoğan Üniversitesi girişimsel olmayan klinik araştırmalar etik kurul başkanlığı tarafından 21.04.2020 tarih ve 2020/55 karar numarası ile bilimsel ve etik yönden uygun bulunmuştur.

\section{BULGULAR}

Dilsel Eşdeğerlik Çalışması: Dilsel Eşdeğerlik çalışması için öncelikle ana dili İngilizce olan ve Türkçe'yi çok iyi konuşan öğretim elemanından yardım istenerek ölçek Türkçe'ye çevrilmiştir. Daha sonra Türkçe'ye çevrilen taslak üzerinden 6 egzersiz psikolojisi alanında çalışan uzman uygun ifade seçimine karar vermiştir. Bir sonraki aşamada ise ana dili Türkçe olan 2 öğretim elemanı ölçeği orijinal dile tekrar çeviride bulunmuştur. Aslı ile karşılaştırılan ölçeğin uygunluğuna araştırmacılar tarafindan karar verilmiştir.

Kapsam Geçerliliği: Kapsam geçerliliği için Lawshe'nin (1975) önerdiği yaklaşım dikkate alınmıştır. Dilsel eşdeğerlik çalışmasında da yer alan uzmanların vermiş oldukları yanıtlar doğrultusunda her bir maddenin Kapsam Geçerliği Oranı (KGO) ve ölçeklerdeki her bir faktörün Kapsam Geçerliği İndeksi (KGI) hesaplanmıştır. Yapılan hesaplamalar sonucunda her bir alt maddenin KGO'ları .80'den her bir faktörün KGI'leri ise .67'den büyük olduğu gözlenmiştir (Wilson vd., 2012; Yurdagül, 2005).

\section{Alt Boyutlu Yapıya İlişkin Bulgular}

Yapı Geçerliliği: Ölçeğin yapı geçerliliği Doğrulayıcı Faktör Analizinden faydalanılmıştır. Takım Sporlarında Paylaşılan Zihinsel Modeller Ölçeği için yapılan DFA sonucunda; modifikasyon endeksi, modelin uyumunun teorik olarak ilgili maddeleri kapsayacak şekilde geliştirilebileceğini ve modelin yeniden belirlendiğini göstermiştir. Analiz sonucunda uyum indeksleri; $\chi 2 / \mathrm{df}=1.779$ mükemmel uyum (Kline, 2011), NFI=0.854 kabul edilebilir uyum (Forza ve Filippini, 1998), RMSEA=0.049 mükemmel uyum (Browne ve Cudeck, 1993), $\mathrm{CFI}=0.929$ kabul edilebilir uyum (Baumgartner ve Homburg, 1996), GFI=0.817 kabul edilebilir uyum (Greenspoona ve Saklofske, 1998) düzeyindedir. Bu sonuçlar modelin verilere iyi uyduğunu düşündürmektedir. 
Tablo 1. 13 Alt boyutlu yapının DFA değerleri

\begin{tabular}{|c|c|c|c|c|c|}
\hline Madde & Alt Boyut & $\begin{array}{c}\text { Standardize } \\
\text { Faktör Yükleri }\end{array}$ & $\begin{array}{l}\text { Faktör } \\
\text { Yükleri }\end{array}$ & $\begin{array}{l}\text { SE (Standart } \\
\text { Hata) }\end{array}$ & t-değeri \\
\hline Madde 1 & Beceriyi maksimuma çıkartma & 0,825 & & & \\
\hline Madde 4 & Beceriyi maksimuma çıkartma & 0,776 & 0,059 & 16,416 & $* * *$ \\
\hline Madde 7 & Beceriyi maksimuma çıkartma & 0,650 & 0,062 & 12,941 & $* * *$ \\
\hline Madde 10 & Beceriyi maksimuma çıkartma & 0,817 & 0,056 & 17,722 & $* * *$ \\
\hline Madde 28 & Takım yeterliliği & 0,749 & & & \\
\hline Madde 24 & Takım yeterliliği & 0,643 & 0,068 & 12,032 & $* * *$ \\
\hline Madde 20 & Takım yeterliliği & 0,792 & 0,072 & 15,225 & $* * *$ \\
\hline Madde 16 & Takım yeterliliği & 0,787 & 0,068 & 15,099 & $* * *$ \\
\hline Madde 49 & Birbirini tanıma & 0,747 & & & \\
\hline Madde 46 & Birbirini tanıma & 0,797 & 0,068 & 15,536 & $* * *$ \\
\hline Madde 42 & Birbirini tanıma & 0,696 & 0,078 & 12,484 & $* * *$ \\
\hline Madde 38 & Birbirini tanıma & 0,709 & 0,069 & 13,606 & $* * *$ \\
\hline Madde 48 & Yaratıcılık & 0,790 & & & \\
\hline Madde 45 & Yaratıcılık & 0,770 & 0,056 & 15,942 & $* * *$ \\
\hline Madde 41 & Yaratıcılık & 0,741 & 0,06 & 15,168 & $* * *$ \\
\hline Madde 37 & Yaratıcılık & 0,689 & 0,059 & 13,836 & $* * *$ \\
\hline Madde 47 & Öngörü & 0,742 & & & \\
\hline Madde 44 & Öngörü & 0,733 & 0,068 & 13,811 & $* * *$ \\
\hline Madde 40 & Öngörü & 0,735 & 0,065 & 13,847 & $* * *$ \\
\hline Madde 36 & Öngörü & 0,723 & 0,069 & 13,584 & $* * *$ \\
\hline Madde 30 & Antrenör-Sporcu Uyumu & 0,871 & & & \\
\hline Madde 31 & Antrenör-Sporcu Uyumu & 0,893 & 0,046 & 21,295 & $* * *$ \\
\hline Madde 32 & Antrenör-Sporcu Uyumu & 0,782 & 0,049 & 17,356 & $* * *$ \\
\hline Madde 13 & Takım hedefleri & 0,695 & & & \\
\hline Madde 17 & Takım hedefleri & 0,754 & 0,083 & 13,185 & $* * *$ \\
\hline Madde 21 & Takım hedefleri & 0,732 & 0,087 & 12,805 & $* * *$ \\
\hline Madde 25 & Takım hedefleri & 0,733 & 0,08 & 12,83 & $* * *$ \\
\hline Madde 29 & Takım hedefleri & 0,652 & 0,088 & 11,447 & $* * *$ \\
\hline Madde 14 & Öz-yeterlilik & 0,759 & & & \\
\hline Madde 18 & Öz-yeterlilik & 0,759 & 0,069 & 14,17 & $* * *$ \\
\hline Madde 22 & Öz-yeterlilik & 0,745 & 0,074 & 13,867 & $* * *$ \\
\hline Madde 26 & Öz-yeterlilik & 0,738 & 0,071 & 13,73 & $* * *$ \\
\hline Madde 3 & Denge & 0,724 & & & \\
\hline Madde 6 & Denge & 0,685 & 0,08 & 12,473 & $* * *$ \\
\hline Madde 9 & Denge & 0,769 & 0,071 & 14,08 & $* * *$ \\
\hline Madde 12 & Denge & 0,688 & 0,078 & 12,536 & $* * *$ \\
\hline Madde 2 & Oyunuların pozisyon uyumu & 0,719 & & & \\
\hline Madde 5 & Oyunuların pozisyon uyumu & 0,716 & 0,073 & 13,109 & $* * *$ \\
\hline Madde 8 & Oyunuların pozisyon uyumu & 0,733 & 0,084 & 13,431 & $* * *$ \\
\hline Madde 11 & Oyunuların pozisyon uyumu & 0,713 & 0,081 & 13,049 & $* * *$ \\
\hline Madde 33 & Oyuncular aras1 uyum & 0,887 & & & \\
\hline Madde 34 & Oyuncular arası uyum & 0,831 & 0,047 & 19,455 & $* * *$ \\
\hline Madde 35 & Oyuncular arası uyum & 0,769 & 0,05 & 17,223 & $* * *$ \\
\hline Madde 27 & Diğerlerinin Yeterliliği & 0,762 & & & \\
\hline Madde 23 & Diğerlerinin Yeterliliği & 0,729 & 0,071 & 13,947 & $* * *$ \\
\hline Madde 19 & Diğerlerinin Yeterliliği & 0,745 & 0,072 & 14,306 & $* * *$ \\
\hline Madde 15 & Diğerlerinin Yeterliliği & 0,741 & 0,072 & 14,218 & $* * *$ \\
\hline Madde 39 & Deneyim & 0,711 & & & \\
\hline Madde 43 & Deneyim & 0,767 & 0,094 & 12,915 & $* * *$ \\
\hline
\end{tabular}

Hair vd., (2014) göre faktör yük değeri 0.50 ve üzeri olan maddeler yapının açıklanmasında anlamlı derecede önemlidir. Standardize faktör yüklerine bakarak, geçerliliğin (convergent validity) sağladığı sonucuna varılmıştır. Ayrıca maddelerin t değerleri kontrol edilmiş ve her birinin $\mathrm{p}<0.05$ anlamlılık düzeyinde olduğu gözlemlenmiştir (Tablo 1.) 
Yakınsak Geçerlik: DFA sonucu ortaya çıkan modelin yakınsak geçerliği değerlendirilmiştir. Takım Sporlarında Paylaşılan Zihinsel Modeller Ölçeğinin ölçüm modellerinin yakınsak geçerliği için faktör yük değerlerinden yola çıkarak ortalama varyans (AVE) ve yapı güvenirliği (CR) hesaplanmıştır. AVE değeri hesaplamalarında tüm alt boyutların .50'den yüksek olduğu görülmüştür (Kline, 2011). Ayrıca genel CR değerinin .70’den büyük değerlere sahip olduğu görülmüştür (Fornell ve Larcker, 1981).

Iraksak Geçerlilik: Ölçülmek istenen yapının faktörleri arasında yüksek korelasyon olmaması ıraksak geçerliği için istenen bir özelliktir. Farklı bir ifade ile ölçek alt boyutlarının aynı özelliği ölçmesi istenmemekte ancak birbirileri ile de uyum içerisinde olması beklenmektedir. Alt boyutlar arasındaki korelasyon düzeylerinin 0.85 'i geçmediği gözlemlenmiştir (Kline, 2011). Tablo 2'de ölçeklerin yapılar arası korelasyon, AVE ve CR değerleri gösterilmektedir.

Tablo 2. 13 Alt boyutlu yapının korelasyon, AVE ve CR değerleri ile güvenirlilik katsayıları

\begin{tabular}{|c|c|c|c|c|c|c|c|c|c|c|c|c|c|c|c|c|}
\hline Alt Boyut & Alfa & 1 & 2 & 3 & 4 & 5 & 6 & 7 & 8 & 9 & 10 & 11 & 12 & 13 & AVE & $\mathbf{C R}$ \\
\hline 1. Beceriyi Maksimuma Çıkartma & .848 & 1 & .78 & .63 & .61 & .63 & .61 & .79 & .73 & .81 & .82 & .62 & .74 & .56 & .59 & .83 \\
\hline 2. Takım Yeterliliği & .830 & & 1 & .69 & .67 & .69 & .62 & .84 & .80 & .74 & .76 & .66 & .84 & .58 & .56 & .83 \\
\hline 3. Birbirini Tanıma & .820 & & & 1 & .85 & .83 & .64 & .71 & .67 & .67 & .60 & .69 & .67 & .70 & .55 & .83 \\
\hline 4. Yaratıcılık & .835 & & & & 1 & .85 & .64 & .69 & .67 & .64 & .63 & .73 & .67 & .71 & .56 & .84 \\
\hline 5. Öngörü & .822 & & & & & 1 & .61 & .68 & .65 & .64 & .61 & .70 & .68 & .73 & .54 & .82 \\
\hline 6. Antrenör Sporcu Uyumu & .880 & & & & & & 1 & .64 & .57 & .58 & .65 & .75 & .57 & .55 & .72 & .85 \\
\hline 7. Takım Hedefleri & .837 & & & & & & & 1 & .79 & .73 & .75 & .64 & .83 & .61 & .51 & .84 \\
\hline 8. Öz Yeterlilik & .835 & & & & & & & & 1 & .72 & .70 & .62 & .80 & .60 & .56 & .84 \\
\hline 9. Denge & .805 & & & & & & & & & 1 & .84 & .61 & .74 & .59 & .51 & .81 \\
\hline 10. Oyunuların pozisyon uyumu & .810 & & & & & & & & & & 1 & .62 & .75 & .60 & .52 & .81 \\
\hline 11. Takım Uyumu & .873 & & & & & & & & & & & 1 & .62 & .62 & .69 & .84 \\
\hline 12. Diğerlerinin Yeterliliği & .831 & & & & & & & & & & & & 1 & .60 & .55 & .83 \\
\hline 13. Deneyim & .802 & & & & & & & & & & & & & 1 & .71 & .77 \\
\hline
\end{tabular}

Güvenirlilik: Takım Sporlarında Paylaşılan Zihinsel Modeller Ölçeği güvenirliğini test etmek amacıyla Cronbach's Alpha iç tutarlık katsayılarından faydalanılmıştır. Alt boyutlar için hesaplanan iç tutarlık katsayılarının yeterli düzeyde olduğu anlaşılmaktadır. Alt boyutların iç tutarlılık katsayıları Tablo 2'de gosterilmiştir (Nunnally ve Bernstein, 1994).

\section{Alt Boyutlu Yapıya İlişkin Bulgular}

Yapı Geçerliliği: Ölçeğin yapı geçerliliği Doğrulayıcı Faktör Analizinden faydalanılmıştır. Takım Sporlarında Paylaşılan Zihinsel Modeller Ölçeği için yapılan DFA sonucunda; modifikasyon endeksi, modelin uyumunun teorik olarak ilgili maddeleri kapsayacak şekilde geliştirilebileceğini ve modelin yeniden belirlendiğini göstermiştir. Analiz sonucunda uyum indeksleri; $\chi 2 / \mathrm{df}=2.973$ kabul edilebilir uyum (Kline, 2011), NFI=0.950 mükemmel uyum (Forza ve Filippini, 1998), RMSEA=0.072 kabul edilebilir uyum (Browne ve Cudeck, 1993), $\mathrm{CFI}=0.962$ mükemmel uyum (Baumgartner ve Homburg, 1996), GFI=0.905 kabul edilebilir uyum (Greenspoona ve Saklofske, 1998) düzeyindedir. Bu sonuçlar modelin verilere iyi uyduğunu düşündürmektedir. 
Tablo 3. 3 Alt boyutlu yapının DFA değerleri

\begin{tabular}{|c|c|c|c|c|c|}
\hline Madde & Alt Boyut & $\begin{array}{c}\text { Standardize } \\
\text { Faktör Yükleri }\end{array}$ & $\begin{array}{l}\text { Faktör } \\
\text { Yükleri }\end{array}$ & $\begin{array}{l}\text { SE (Standart } \\
\text { Hata) }\end{array}$ & t-değeri \\
\hline Öngörü & Durumsal Bilişsellik & 0,911 & & & \\
\hline Birbirini Tanıma & Durumsal Bilişsellik & 0,922 & 0,035 & 27,968 & $* * *$ \\
\hline Yaratıcilık & Durumsal Bilişsellik & 0,931 & 0,034 & 28,791 & $* * *$ \\
\hline Deneyim & Durumsal Bilişsellik & 0,779 & 0,050 & 19,013 & $* * *$ \\
\hline Özyeterlilik & Yeterlilik İnançları & 0,872 & & & \\
\hline Diğerlerinin Yeterliliği & Yeterlilik İnançları & 0,906 & 0,044 & 23,969 & $* * *$ \\
\hline Takım Yeterliliği & Yeterlilik İnançları & 0,922 & 0,042 & 24,950 & $* * *$ \\
\hline Beceriyi Maksimuma Çıkartma & Genel Billişsellik & 0,874 & & & \\
\hline Oyuncuların pozisyon uyumu & Genel Billişsellik & 0,853 & 0,045 & 21,258 & $* * *$ \\
\hline Denge & Genel Billişsellik & 0,843 & 0,045 & 20,762 & $* * *$ \\
\hline Antrenör Sporcu Uyumu & Genel Billişsellik & 0,706 & 0,059 & 15,400 & $* * *$ \\
\hline Takım Uyumu & Genel Billişsellik & 0,735 & 0,052 & 16,382 & $* * *$ \\
\hline Takım Hedefleri & Genel Billişsellik & 0,909 & 0,039 & 24,341 & $* * *$ \\
\hline
\end{tabular}

Modelin uyum indeks değerleri analiz programının önerdiği modifikasyon sonucunda iyileştirilmiştir. Model uyum indeksleri "Genel Bilișsellik" boyutu altında bulunan takım uyumu ve antrenör-sporcu uyumu $(\mathrm{r}=0.20)$ arasında yapilan modifikasyon sonucu elde edilmiştir. Hair vd. (2014) göre faktör yük değeri 0.50 ve üzeri olan maddeler yapının açılanmasında anlamlı derecede önemlidir. Standardize faktör yüklerine bakarak, geçerliliğin (convergent validity) sağladığı sonucuna varılmıştır. Ayrıca maddelerin $t$ değerleri kontrol edilmiş ve her birinin $\mathrm{p}<0.05$ anlamlılık düzeyinde olduğu gözlemlenmiştir (Tablo 3.)

Yakınsak Geçerlik: DFA sonucu ortaya çıkan modelin yakınsak geçerliği değerlendirilmiştir. Takım Sporlarında Paylaşılan Zihinsel Modeller Ölçeğinin 3 boyutlu ölçüm modellerinin yakınsak geçerliği için faktör yük değerlerinden yola çıkarak ortalama varyans (AVE) ve yapı güvenirliği (CR) hesaplanmıştır. AVE değeri hesaplamalarında tüm alt boyutların 0,50'den yüksek olduğu görülmüştür (Kline, 2011). Ayrıca genel CR değerinin 0.70’den büyük değerlere sahip olduğu görülmüştür (Fornell ve Larcker, 1981).

Iraksak Geçerlilik: Ölçülmek istenen yapının faktörleri arasında yüksek korelasyon olmaması ıraksak geçerliği için istenen bir özelliktir. Farklı bir ifade ile ölçek alt boyutlarının aynı özelliği ölçmesi istenmemekte ancak birbirileri ile de uyum içerisinde olması beklenmektedir. Alt boyutlar arasındaki korelasyon düzeylerinin 0.85 'i geçmediği gözlemlenmiştir (Kline, 2011). Tablo 4'de ölçeklerin yapılar arası korelasyon, AVE ve CR değerleri gösterilmektedir.

Tablo 4. 3 Alt boyutlu yapının korelasyon, AVE ve CR değerleri ile güvenirlilik katsayıları

\begin{tabular}{lcccccc}
\hline Alt Boyut & Alfa & DB & Yi & GB & AVE & CR \\
\hline Durumsal Bilisssellik & 0,930 & 1 & 0,761 & 0,803 & 0,788 & 0,937 \\
Yeterlilik İnançları & 0,928 & & 1 & 0,832 & 0,81 & 0,928 \\
Genel Bilişsellik & 0,931 & & & 1 & 0,678 & 0,926 \\
\hline
\end{tabular}

Güvenirlilik: Takım Sporlarında Planlamış Mental Modeller Ölçeği güvenirliğini test etmek amacıyla Cronbach's Alpha iç tutarlık katsayılarından faydalanılmıştır. Alt boyutlar için hesaplanan iç tutarlık katsayılarının yeterli düzeyde olduğu anlaşılmaktadır. Alt boyutların iç tutarl11ık katsayıları Tablo 4'te gösterilmiştir (Nunnally ve Bernstein, 1994). 


\section{TARTIŞMA VE SONUÇ}

Paylaşılan Zihinsel Modeller (PZM), iletişim sınırlı olduğu hatta olmadığı zamanlarda ekip koordinasyonunu sağlayan, takımla ilgili bilişsel süreci yöneten bir dinamiktir. Açık iletişimin sınırlı olduğu ve birçok eylemin kontrol edilemez olduğu takım sporlarında, PZM'nin rolü oldukça önemlidir (Reimer, Park ve Hinsz, 2006). Bu durum baskı altında daha da belirginleşir (Entin ve Serfaty, 1999). Spor alanındaki bu çeşitliliğe rağmen, PZM kavramı şimdiye kadar çoğunlukla askeri, eğitimsel ve endüstriyel / organizasyonel ortamlarda incelenmiştir.

Bu araştırma kapsamında Takım Sporlarında Paylaşılan Zihinsel Modeller Ölçeği (TSPZMÖ) Türkçe formu oluşturulmuş ve psikometrik özelliklerinin incelenmesi amacıyla geçerlik ve güvenirlik analizi yapılmıştır. Yapılan analizler sonucunda geçerlik ve güvenirlik testlerinden elde edilen puanlar TSPZMÖ 49 maddeli 13 alt faktörlü ve 3 üst faktörlü (ölçekli) yapısını desteklemektedir. Ölçeğin geçerliği için kapsam geçerliliği, yap1 geçerliği, yakınsak ve rraksak geçerliği incelenmiştir. Yapılan hesaplamalar sonucunda her bir alt maddenin KGO'ları 0,80'den her bir faktörün KGI'leri ise 0,67'den büyük olduğu gözlenmiştir Ortaya çıkan bu sonucun kapsam geçerliliği için yeterli düzeyde olduğu anlaşılmaktadır (Wilson vd., 2012; Yurdagül, 2005). 13 alt boyutlu yapının yapı geçerliği için yapılan DFA sonucunda elde edilen uyum indeksleri, $\chi 2 / \mathrm{sd}=1.779, \mathrm{GFI}=0,817, \mathrm{CFI}=0,929, \mathrm{NFI}=0,854$ ve RMSEA $=0.049 ; 3$ alt boyutlu yapının yapı geçerliliği için yapılan DFA sonucunda elde edilen uyum indeksleri ise $\chi^{2} / \mathrm{sd}=2.973, \quad \mathrm{GFI}=0,905, \quad \mathrm{CFI}=0,962, \quad \mathrm{NFI}=0,950 \quad$ ve RMSEA $=0.072$ olarak bulunmuştur. DFA'nın RMSEA değerinin .05 ile .08 arasında olması iyi uyum gösterdiğine, .05'den küçük olmasının ise mükemmel uyuma işaret ettiğini işaret etmektedir (Browne ve Cudeck, 1993; Byrne, 1998; Hu ve Bentler, 1999; Mc Donald ve Moon-Ho, 2002; Kelloway, 1998; Schmelleh-Engel vd., 2003). Ölçeğimizde bu değer 13 alt boyutlu yapıda 0,049; 3 alt boyutlu yapıda ise 0.072 olarak ortaya çıkmıştır. Ayrıca Baumgartner ve Homburg (1996), Marsh vd. (2006), Hu ve Bentler (1999) ve SchmellehEngel vd.'nin (2003) belirtmiş olduğuna göre GFI, IFI, CFI, ve NFI değerleri .90 ile .95 arasında iyi değerleri $.95^{\prime}$ ten büyük olması ise mükemmel uyuma işaret etmektedir. Ayrıca Greenspoona ve Saklofske (1998) ve Forza ve Filippini (1998) özellikle $\chi 2 /$ sd değerlerinin iyi uyum göstermesi durumunda GFI ve NFI değerlerinde .80'den büyük olmasının; kabul edilebilir uyum içerisinde incelenebileceğinden bahsetmiştir. Bu araştırma kapsamında hem 13 alt boyutlu yapının hem de 3 alt boyutlu yapının uyum indeksleri incelendiğinde ölçeklere ait uyum değerlerinin kimisinin mükemmel kimisinin ise kabul edilebilir sınırlar içinde olduğu görülmektedir. Bu sonucun ölçeğin orijinal versiyonundaki değerlerle de benzerlik içinde olduğu anlaşılmaktadır (Gershgoren, 2012).

Takım Sporlarında Paylaşılan Zihinsel Modeller Ölçeği yakınsak geçerliliği hakkında bilgi edinmek için AVE ve CR değerleri hesaplanmıştır. AVE değerleri incelendiğinde tüm alt boyutların değerlerinin referans değer olan 0.50 'den düşük olduğu görülmektedir. AVE değerinin 0.50'den büyük olması gerektiğini belirten kaynakların (Hair vd., 2010) yanında 0.40 ile 0.50 değerleri arasında da kabul edileceğini belirten kaynaklara rastlamak mümkündür (Huang vd., 2013). Tüm alt boyutların yapı güvenirliliği (CR) incelendiğinde ise 0,70 değerinin üzerinde değerlere sahip oldukları anlaşılmaktadır (Fornell ve Larcker, 1981). Ölçülmek istenen yapının faktörleri arasında yüksek korelasyon olmaması 1raksak geçerliğin 
ön koşuludur. Ölçeğin kendi alt boyutları arasında korelasyon düzeylerinin Kline'ın (2011) önermiş olduğu 0,85 'i geçmediği gözlemlenmiştir. Bu nedenle elde edilen bu bulgular 1şığında ölçeğin yakınsak ve ıraksak geçerliğinin de desteklendiği düşünülmektedir.

Ölçeğin güvenirliliği için Cronbach's Alpha iç tutarlık katsayısı hesaplanmıştır. Kline'a (2011) göre korelasyon katsayısının 0.90 düzeyinde mükemmel, 0.80 düzeyinde çok iyi ve 0.70 düzeyinde ise yeterli olduğu ifade edilmektedir. Buna göre alt boyutlara ait güvenirlilik katsayılarının çok iyi ve mükemmel düzeyde değiştiği söylenebilir.

Tüm bu bilgiler 1şı̆̆ında Takım Sporlarında Paylaşılan Zihinsel Modeller Ölçeği'nin Türk sporcu grubu için geçerli ve güvenilir bir ölçme aracı olduğu söylenebilir. TSPZMÖ, sporda ayrıntılı bir paylaşılan zihinsel modellere dayanarak geliştirildiğinden, 13 alt boyut büyük önem taşımaktadır. Bu nedenle, TSPZMÖ, bize (a) oyunculardan beklenen becerilerin yetersizliği, (b) yetersiz yaratıcılık, (c) oyuncular arasındaki uyumsuzluk, (d) spordaki deneyim eksikliği, (e) uygunsuz oyun planı, (f) oyuncuların mevkileri konusundaki anlaşmazlıkları, (g) dengesiz oyuncuların özellikleri, (h) antrenör ve takım felsefesinde yer alan oyuncular arasındaki anlaşmazlıklar, (i) oyuncular arasındaki gerekli olan tutumlar konusunda anlaşmazlık ve stratejiler, (j) eksik veya tutarsız takım hedefleri, (k) oyuncuların yeterli veya yetersiz öz-yeterlikleri, (l) takım arkadaşlarının yeteneklerine inanmaması veya (m) takım arkadaşları hakkındaki şüpheler hakkında takımın eksikleri açısından bize önemli bilgiler vermektedir. TSPZMÖ bir takım olabilmek için gerekli unsurlar hakkında bize bilgiler verir. Bu çerçevede, antrenörler ve spor psikologları, takımlarını ileriye taşımak için bu unsurları anlama adına TSPZMÖ’yi kullanabilir. Ayrıca TSPZMÖ'yi takımlarının performanslarını geliştirmek adına kullanacakları bir müdahale programı üretmek veya uyarlamak için kullanabilirler.

\section{KAYNAKLAR}

Apitzsch, E. (2009). Coaches' and elite team players' perception and experiencing of collective collapse. Athletic Insight, 1 (2), 57-74.

Arnesen, M. (2019). Felles mentale modeller blant håndballspillere. Master Thesis. University of Stavanger, Norway.

Backer, J., Cote, J. \& Abernethy, B. (2003). Sport-specific practice and the development of expert decisionmaking in team ball sports. Journal of Applied Sport Psychology, 15(1), 12-25. https://doi.org/10.1080/10413200305400.

Baumgartner, H. \& Homburg, C. (1996). Applications of structural equation modeling in marketing and consumer research: A review. International journal of Research in Marketing, 13(2), 139-161. https://doi.org/10.1016/0167-8116(95)00038-0.

Bourbousson, J. Poizat, G., Saury, J., \& Seve, C. (2010). Team coordination in basketball: Description of the cognitive connections among teammates. Journal of Applied Sport Psychology, 22(2), 150-166. https://doi.org/10.1080/10413201003664657.

Browne, M.W. \& Cudeck, R. (1993). Alternative ways of assessing model fit. In: Bollen, K.A., \& Long, J.S. (Eds.), Testing structural equation models (pp. 136-162). Beverly Hills, CA: Sage. https://doi.org/10.1177/0049124192021002005.

Burke, C. S., Stagl, K. C., Salas, E., Pierce, L. \& Kendall, D. (2006). Understanding team adaptation: A conceptual analysis and model. Journal of Applied Psychology, 91(6), 1189-1207. https://doi.org/10.1037/0021-9010.91.6.1189. 
Byrne, B. M. (2010). Structural equation modeling with AMOS: basic concepts, applications, and programming (multivariate applications series). New York: Taylor \& Francis Group, 396, 7384.

Cannon-Bowers, J. A. \& Bowers, C. (2006). Applying work team results to sports teams: Opportunities and cautions. International Journal of Sport and Exercise Psychology, 4(4), 447-462. https://doi.org/10.1080/1612197X.2006.9671807.

Converse, S., Cannon-Bowers, J. A. \& Salas, E. (1993). Shared mental models in expert team decision making. Individual and group decision making: Current issues, 221, 221-46.

Craik, K. J. W. (1943). The Nature of explanation. Cambridge: Cambridge University Press. https://doi.org/10.1017/S0031819100004733.

Eccles, D. W. \& Tenenbaum, G. (2004). Why an expert team is more than a team of experts: A socialcognitive conceptualization of team coordination and communication in sport. Journal of Sport \& Exercise Psychology, 26(4), 542-560. https://doi.org/10.1123/jsep.26.4.542.

Entin, E. E. \& Serfaty, D. (1999). Adaptive team coordination. Human factors, 41(2), 312-325. https://doi.org/10.1518/001872099779591196.

Fornell, C. \& Larcker, D.F. (1981). Evaluating structural equation models with unobservable variables and measurement error. Journal of Marketing Research, 18(1), 39-50. https://doi.org/10.2307/3151312.

Forza, C. \& Filippini, R. (1998). TQM impact on quality conformance and customer satisfaction: A causal model. International Journal of Production Economics, 55(1), 1-20. https://doi.org/10.1016/S0925-5273(98)00007-3.

Gershgoren, L. (2012). The development and validation of the shared mental models in team sports questionnaire. Electronic Theses, Treatises and Dissertations. Florida State University, Tallahassee, FL.

Gershgoren, L., Filho, E. M., Tenenbaum, G. \& Schinke, R. J. (2013). Coaching shared mental models in soccer: A longitudinal case study. Journal of Clinical Sport Psychology, 7(4), $293-312$. https://doi.org/10.1123/jcsp.7.4.293.

Giske, R., Rodahl, S. E. \& Høigaard, R. (2015). Shared mental task models in elite ice hockey and handball teams: Does it exist and how does the coach intervene to make an impact?. Journal of Applied Sport Psychology, 27(1), 20-34. https://doi.org/10.1080/10413200.2014.940431.

Goldschmidt, G. (2017). Manual sketching: Why is it still relevant?. In The Active Image (pp. 77-97). Springer, Cham. https://doi.org/10.1007/978-3-319-56466-1_4.

Goldschmidt, G. \& Surasky, T. (2011). The Use of Graphic Representations in Semiconductor Engineering Team Problem Solving. In ICORD 11: Proceedings of the 3rd International Conference on Research into Design Engineering, Bangalore, India, 10.-12.01. 2011.

Greenspoon, P.J. \& Saklofske, D.H. (1998). Confirmatory factor analysis of the multidimensional students' life satisfaction scale. Personality and Individual Differences, 25(5), 965-971.

Hair, J. F., Black, W. C., Babin, B. J., Anderson, R. E. \& Tatham, R. L. (1998). Multivariate data analysis (Vol. 5, No. 3, pp. 207-219). Upper Saddle River, NJ: Prentice hall.

Hu, L. T. \& Bentler, P. M. (1999). Cutoff criteria for fit indexes in covariance structure analysis: Conventional criteria versus new alternatives. Structural equation modeling: a multidisciplinary journal, 6(1), 1-55. https://doi.org/10.1080/10705519909540118.

Huang, C. C., Wang, Y. M., Wu, T. W. \&Wang, P. A. (2013). An empirical analysis of the antecedents and performance consequences of using the moodle platform. International Journal of Information \& Education Technology, 3(2), 217-221. https://doi.org/10.7763/IJIET.2013.V3.267.

Kelloway, E. K. (1998). Using LISREL for structural equation modeling: A researcher's guide. Thousand Oaks, California: Sage. 
Kline, R.B. (2011). Principles and practice of structural equation modeling (Third Edition). New York: Guilford Press.

Langan-Fox, J., Anglim, J. \& Wilson, J. R. (2004). Mental models, team mental models, and performance: Process, development, and future directions. Human Factors and Ergonomics in Manufacturing \& Service Industries, 14(4), 331-352. https://doi.org/10.1002/hfm.20004.

Lawshe, C.H. (1975). A quantitative approach to content validity. Personnel psychology, 28(4), 563-575.

Marsh, H.W., Hau, K.T., Artelt, C., Baumert, J. \& Peschar, J.L. (2006). OECD's brief self-report measure of educational psychology's most useful affective constructs: Cross-cultural, psychometric comparisons across 25 countries. International Journal of Testing, 6(4), 311-360. https://doi.org/10.1207/s15327574ijt0604_1.

McDonald, R. P. \& Ho, M. H. R. (2002). Principles and practice in reporting structural equation analyses. Psychological methods, 7(1), 64-82. https://doi.org/10.1037//1082-989X.7.1.64.

Nunnally, J. C. \& Bernstein, I.H. (1994). Psychometric theory. New Delhi: Tata McGraw-Hill Education

Reimer, T., Park, E. S. \& Hinsz, V. B. (2006). Shared and coordinated cognition in competitive and dynamic task environments: An information-processing perspective for team sports. International Journal of Sport and Exercise Psychology, 4(4), 376-400. https://doi.org/10.1080/1612197X.2006.9671804.

Rouse, W. B. \& Morris, N. M. (1986). On looking into the black box: Prospects and limits in the search for mental models. Psychological bulletin, 100(3), 349-363. https://doi.org/10.1037/0033-2909.100.3.349

Sartre, J.P. (2002). Fotboldholdet som gruppe den gode malvakt. In P. Christensen \& F. Stjernefelt (Ed.), Fodbold: forfattere om fonomenet fotbold [Soccer: Authors on football as a phenomena] Kobenhavn. Denmark: Gyldendal.

Schermelleh-Engel, K., Moosbrugger, H. \& Müller, H. (2003). Evaluating the fit of structural equation models: Tests of significance and descriptive goodness-of-fit measures. Methods of psychological research online, 8(2), 23-74.

Ward, P. \& Eccles, D.W. (2006). A commentary on team cognition and expert teams: Emerging insights into performance for exceptional teams. International Journal of Sport and Exercise Psychology, 4(4), 463483. https://doi.org/10.1080/1612197X.2006.9671808.

Wilson, F.R., Pan, W. \& Schumsky, D.A. (2012). Recalculation of the critical values for Lawshe's content validity ratio. Measurement and Evaluation in Counseling and Development, 45(3), 197-210. https://doi.org/10.1177/0748175612440286.

Yazıcı, E. ve Düzkaya, H. (2016). Dünya kalkınma raporu 2015 perspektifinden yoksulluk, çocuk gelişimi, ev idaresi ve verimliliğe yeniden bakış. Türkiye Sosyal Araşttrmalar Dergisi, 20(3), 611-631.

Yazıcı, G. (2018). Tasarım ortamında etkileşimli imgelem ve paylaşılan zihinsel modeller arasındaki ilişki. Yüksek Lisans Tezi, İzmir Yüksek Teknoloji Enstitüsü, İzmir.

Yurdagül, H. (2005). Ölçek geliştirme çalışmalarında kapsam geçerliği için kapsam geçerlik indekslerinin kullanılması. 14. Ulusal Eğitim Bilimleri Kongresi, Denizli.

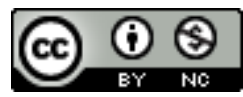

Bu eser Creative Commons Atıf-GayriTicari 4.0 Uluslararası Lisansı ile lisanslanmıştır. 